review

\title{
Locally recurrent rectal cancer: treatment options
}

\author{
Vaneja Velenik \\ Department of Radiotherapy, Institute of Oncology Ljubljana, Slovenia
}

\begin{abstract}
Background. Although the preoperative radiochemotherapy and the optimised surgical technique have improved the outcome in patients with rectal cancer, the local recurrence still remains a therapeutic problem. In up to $50 \%$ of patients the local recurrence appears without simultaneous distant metastases. This review highlights current treatment options of locally recurrent rectal cancer.

Conclusions. The optimal management of the isolated local recurrence remains a difficult and controversial issue. The radical surgical resection is the mainstay of the curative treatment, but an extended surgery can be associated with significant morbidity and impaired quality of life. The preoperative chemoradiation for turnout down staging increases the chance of resectability and the addition of intraoperative radiotherapy may further improve the local control and survival. Re-irradiation is feasible in patients who already received irradiation as part of the primary rectal cancer treatment.
\end{abstract}

Key words: locally recurrent - rectal cancer; multi-modality therapy

\section{Introduction}

The local recurrence (LR) of rectal cancer occurs in up to $30 \%$ of patients who had undergone only the radical resection. The introduction of total mesorectal excision (TME) has reduced the rate of $\mathrm{LR}$ to $<10 \%{ }^{1,2}$ and to $\leq 6 \%$ when TME has been combined with the preoperative radiotherapy alone or combined with chemotherapy. ${ }^{3,4}$ Seventy-five percent of LR are detected within two years from diagnosing

Received 28 May 2009

Accepted 6 June 2009

Correspondence to: Assist. Prof. Vaneja Velenik, MD, PhD, Department of Radiotherapy, Institute of Oncology Ljubljana, Zaloška c. 2, 1000 Ljubljana, Slovenia. Phone: +386 15879 661; Fax: +386 15879 304; E-mail: vvelenik@onko-i.si primary tumor. ${ }^{5}$ From $20 \%$ to $50 \%$ of patients with LR have isolated the local recurrence without distant metastasis. LR may be accompained with pain, bleeding or constipation, depending on the type of the previous surgery. The management of the isolated locoregional recurrence is difficult and treatment options may be limited in patients who have already received a local radiation therapy for the primary rectal cancer. In the absence of the surgical intervention, the 5 -year survival of these patients is less than $4 \%$ and the median survival of 8 months. ${ }^{6,7}$

The choice of therapy depends upon disease location, extent and prior treatment. Predictors for the outcome in patients who received radiotherapy for locally recurrent rectal cancer were performance status, stage, chemotherapy, surgery, extent of resection, histologic grading, and like in other 
localization haemoglobin levels both before and during radiotherapy. ${ }^{8,9}$ Radical surgery (R0) remains the mainstay of the treatment for achieving the longterm local control and survival for locally recurrent rectal cancer (LRRC), but many times an aggressive multimodality approach is required to accomplish negative margins and a chance of cure.

\section{Predictors of local recurrence}

Many factors affect the risk of the local recurrence. The risk increases with the advanced stage ${ }^{10}$ and adverse pathological features of primary tumour, including perineural and vascular invasion and grade. ${ }^{11}$ LR is more likely associated with tumours located in distal rectum, the presence of obstruction or perforation and tumour fixation to adjacent structures. ${ }^{12}$ The significance of the involvement of lateral or circumferential resection margin (CRM) as an independent prognostic factor for LR and the survival has been confirmed in a prospective randomised study on 190 patients who underwent the curative resection of rectal cancer. The rate of CRM involvement was $25 \%$; among those with clear margins, $90 \%$ remained free of pelvic recurrence at 5 years, whereas only $23 \%$ of those with the lateral margin involvement were without LR. ${ }^{13}$

Recently published data from Davis et al. showed that there was no difference in the incidence of LR after sphincter-saving resections compared to the abdominoperineal excision, as long as the appropriate technique was used, the distal margin of clearance was at least $1 \mathrm{~cm}$ and CRM margins were free of tumour. By avoiding continuing the TME dissection into the pelvic floor and removing low lying tumours en block with the surrounding levator, the rate of involved CRM was reported to be $0 \%$ and the LR rate only $5 \% .{ }^{14}$ As LR after both surgical procedures most commonly arise from residual extramucosal disease, the incomplete removal of the potentially tumourbearing mesorectum is the main cause of LR. ${ }^{15}$ There is a different level of training and experience performing $»$ total mesorectal excision « (TME) among surgeons, resulting in wide range of LR in published reports. A study comparing local recurrence rates after the rectal cancer resection in a group of Canadian surgeons showed that patients of surgeons who had additional training or expertise in colorectal surgery had a local relapse rate of $13 \%$, compared with $34 \%$ in general surgeons' group whose practice included fewer of these operations. ${ }^{16}$ Finally, the rate of LR in patents receiving preoperative or postoperative radiotherapy, either alone or combined with chemotherapy, is reduced comparing with patients treated with surgery alone. More favourable local control rates were reported in series using the preoperative approach. ${ }^{14,15}$

\section{Surgery}

The only chance for the curative treatment of isolated LR is provided by the radical reresection. ${ }^{17}$ Several studies have analyzed factors which could help to select patients with LRRC for surgery i.e. that might predict resectability and, consequently, prognosis. Results are controversial. However, factors most often associated with the increased chance of the radical resection were younger age, female gender, prior local excision or restorative surgery that was performed at another institution. The poorer outcome was related to the presence of pain (as a symptom of LR), lateral tumour extension, increasing number of sites of the recurrent tumour fixation in the pelvis and elevated CEA level before the re-resection. ${ }^{18}$

Surgical procedures available in LRRC are low anterior resection, abdominoperineal resection, pelvic exenteration and ab- 
Table 1. Locally recurrent rectal cancer - external beam radiation without or with intraoperative radiation

\begin{tabular}{|c|c|c|c|c|c|c|}
\hline Author & Year & $\begin{array}{l}\text { Patients } \\
\text { (n) }\end{array}$ & Therapy & $\begin{array}{l}\text { Survival } \\
\text { (\%) }\end{array}$ & $\begin{array}{l}\text { Local } \\
\text { relapse (\%) }\end{array}$ & $\begin{array}{l}\text { Distant } \\
\text { relapse (\%) }\end{array}$ \\
\hline Gunderson et al..$^{30}$ & 1996 & 123 & EBRT/CT $\rightarrow$ surg $\rightarrow$ IORT & $5 y, 20$ & $5 y, 37$ & $5 y, 72$ \\
\hline Lowy et al. ${ }^{31}$ & 1996 & 43 & $\mathrm{EBRT} / \mathrm{CT} \rightarrow$ surg $\rightarrow \mathrm{IOHDR}$ & $2 y, 58$ & $2 y, 36$ & - \\
\hline \multirow{2}{*}{ Farouk et al. ${ }^{32}$} & \multirow{2}{*}{1997} & 116 & EBRT $\rightarrow$ surg & $5 y, 7$ & $3 y, 93$ & $3 y, 54$ \\
\hline & & 64 & $\mathrm{EBRT} \rightarrow$ surg $\rightarrow$ IORT & $5 y, 18$ & $5 y, 27$ & $5 y, 75$ \\
\hline \multirow[t]{2}{*}{ Wong et al. ${ }^{29}$} & \multirow[t]{2}{*}{1998} & 519 & EBRT & $5 y, 5$ & $5 y, 93$ & - \\
\hline & & 94 & EBRT & $3 y, 14$ & $3 y, 90$ & - \\
\hline \multirow[t]{2}{*}{ Mannaerts et al. ${ }^{33}$} & \multirow[t]{2}{*}{2001} & 19 & EBRT $\rightarrow$ surg & $3 y, 11$ & $3 y, 86$ & - \\
\hline & & 33 & $\mathrm{EBRT} \rightarrow$ surg $\rightarrow \mathrm{IORT}$ & $3 y, 60$ & $3 y, 27$ & - \\
\hline \multirow{2}{*}{ Wiig et al. ${ }^{34}$} & \multirow{2}{*}{2002} & 48 & EBRT/CT $\rightarrow$ surg & $5 y, 30$ & $5 y, 70$ & - \\
\hline & & 59 & $\mathrm{EBRT} / \mathrm{CT} \rightarrow$ surg $\rightarrow \mathrm{IORT}$ & $5 y, 30$ & $5 y, 50$ & - \\
\hline Rades et al. ${ }^{35}$ & 2008 & 84 & EBRT $+/-$ CT $\rightarrow$ surg & $3 y, 36$ & $3 y, 67$ & 41 \\
\hline
\end{tabular}

Abbreviations: EBRT - external beam radiotherapy; CT - chemotherapy; IORT - intraoperative radiation.

dominosacral composite resection, and the decisions on the most appropriate one depends upon the site and extend of LR. The anastomotic recurrence without fixation to surrounding structures may be cured by the surgical resection alone in as many as $50 \%$ of cases. ${ }^{19}$ In more extensive cases, sacrectomy with pelvic reconstruction is required to achieve a complete resection and 5-year survival rates in the range of 20$35 \%$ have been reported. ${ }^{19,20}$ The resection with negative microscopical margins can be achieved in approximately $45 \%$ of cases (range 10-67\%). ${ }^{21-23}$ Results of surgical resection alone with positive margins left behind are poor, with less than $10 \%$ of those patients surviving 3 years and no 5-year survivors. ${ }^{24}$ Because of the significant perioperative morbidity and the poor survival outcome extended surgery is not very popular. ${ }^{25}$ On the other hand, untreated LR significantly reduces the quality of life which became more and more important in the treatment of oncological patients. ${ }^{26.27}$ Furthermore, Miller et al. argued that the aggressive surgical treatment of LR improved survival, favourably affected quality of life and represented a cost-effective use of resources. ${ }^{28}$

\section{Combined modality treatment in pa- tients with LR undergoing curative surgery for primary rectal cancer}

Despite the radical resection of LRRC, in $25 \%$ to $61 \%$ of patients another recurrence developed locally or disease progressed systemically. $^{25}$ In addition, external beam radiotherapy (EBRT) alone (i.e. not being accompanied with surgery) or in combination with 5- fluorouracil (5-FU) chemotherapy has only a palliative effect and offers no hope for cure. It allows a temporary symptomatic improvement in majority of patients, but the median duration of symptom relief is only a few months and the 5-year survival is usually less than $5 \%{ }^{29}$ Because of the generally poor results achieved with the surgical resection or EBRT alone, the logical approach for LRRC seemed to be the combination of both modalities.

The effect of the preoperative chemoradiation (45-55 Gy in 5-6 weeks) with 5-fluorouracil (5-FU) chemotherapy in previously nonirradiated patients is supported by data from retrospective series (Table 1). To further increase the response rate and consequently to reduce the need for extensive surgery, improve resectability, local control and survival, other 
chemotherapy agents (CPT-11, oxaliplatin, capecitabine) and targeted agents may be of benefit in the future.

According to above mentioned reports, the EBRT doses to the whole pelvis usually should not exceed 50 Gy because small bowel toxicity restricts delivery of higher dose. However, this dose is insufficient to sterilize gross residual disease after the surgery. ${ }^{36}$ With the use of intraoperative irradiation (IORT) or high-dose rate brachytherapy (IOHDR), a boost of ionizing radiation can be given directly to the parts of tumour resection bed that are most prone for recurrence, yet avoiding irradiation of surrounding normal structures. IORT can achieve the biologic equivalent dose of 2 to 3 times that of the same dose delivered using conventionally fractionated EBRT. ${ }^{30}$ The combination with IORT allows the reduction of the EBRT dose which - together with the physical removal of healthy normal structures from IORT field - reduces toxicity of this modality and potentially improve the therapeutic ratio. IORT has generally been delivered by accelerator-generated electron beam or high-dose rate (HDR) brachytherapy using gamma rays or beta rays emitted by the encapsulated radioactive sources inserted during the surgery, to a total dose in a range of 10-30 Gy. The treatment with IORT requires a dedicated operating suite or transfer of the anesthetized patient from the operating room to the radiotherapy suite. For the mobile HDR-IORT machine, a shielded facility is necessary. Recently, mobile IORT machines were constructed which can be used in conventional hospitals on a daily basis and shared between several operating rooms.

As the IORT facilities are available only in a very limited number of radiotherapy centres, treatment results in the literature are rare and conflicting. While Wiig et al. ${ }^{34}$ showed that IORT did not modify the outcome after the surgery, regardless of the volume of residual disease, reports from some centres suggest that improved the local control and the survival can be achieved in selected patients when the combination of preoperative chemoradiotherapy, radical surgery and IORT is implemented. Five-year survival rates of $18 \%$ to $30 \%$ and local control rates of $50 \%$ to $73 \%$ were reported (Table 1). ${ }^{30-35}$ Recently, a comparison of various treatment combinations revealed significantly improved survival, disease-free survival, and local control rates at 3 years of $60 \%, 43 \%$, and $73 \%$, respectively, when the combination of EBRT, surgery, and IORT was used. ${ }^{33}$ The most frequently observed IORTrelated toxicities were ureteral stenosis $(6 \%)$ and peripheral neuropathy $(16 \%-34 \%) .{ }^{30,33}$ Similarly, a relationship between IORT dose and the incidence of Grade 2 or 3 neuropathy was also demonstrated by Gunderson et al., although not reaching the level of statistical significance $(\leq 12.5$ Gy vs. $\geq 15$ Gy, $7 \%$ vs. $19 \% ; p=0.12) .{ }^{30}$

\section{Multimodality treatment in patients with LR who have received previous external beam radiation therapy}

The anatomic location of local failure after the "optimized" rectal cancer surgery was studied by Syk et al. ${ }^{37}$ All recurrences were found within the irradiated volume in the low pelvis, anatomically below the S1-S2 interspace, if the patients had undergone preoperative radiotherapy or if they had not. ${ }^{37}$ Similar results were reported by Yu et al. with only a limited number of marginal and out-of-field failures, indicating that standard pelvic radiotherapy fields are appropriate for most rectal cancer patients. Of the in-field recurrences, nearly $80 \%$ occurred in the low pelvic and presacral regions. ${ }^{38}$

As a majority of patients with LR have already received the local radiation therapy in neoadjuvant or adjuvant setting during the primary rectal cancer treatment and because of fear of a high probability of severe late toxicity related to the Re-RT, patients are usually 
Table 2. Locally recurrent rectal cancer - treatment of previously irradiated patients

\begin{tabular}{|c|c|c|c|c|c|c|}
\hline First author & $\begin{array}{l}\text { Patients } \\
\text { (n) }\end{array}$ & Year & Therapy & $\begin{array}{l}\text { Survival } \\
(\%)\end{array}$ & $\begin{array}{l}\text { Local } \\
\text { relapse (\%) }\end{array}$ & $\begin{array}{l}\text { Distant } \\
\text { relapse (\%) }\end{array}$ \\
\hline Alektiar et al. ${ }^{44}$ & 74 & 2000 & surg $\rightarrow \mathrm{IOHDR} \pm \mathrm{EBRT} \pm \mathrm{CT}$ & $5 y, 23$ & 61 & 38 \\
\hline Haddock et al. ${ }^{41}$ & 51 & 2001 & $\mathrm{EBRT} \pm \mathrm{CT}+$ surg $+\mathrm{IORT}$ & $5 y, 12$ & $5 y, 66$ & $5 y, 76$ \\
\hline Lindel et al. ${ }^{45}$ & 69 & 2001 & $\mathrm{EBRT} / \mathrm{CT} \rightarrow$ surg $\rightarrow \mathrm{IORT}$ & 27 & 65 & - \\
\hline Mohiuddin et al. ${ }^{46}$ & 103 & 2002 & $\mathrm{EBRT} / \mathrm{CT} \rightarrow$ surg & 19 & - & - \\
\hline Valentini et al. ${ }^{47}$ & 59 & 2003 & $\mathrm{EBRT} / \mathrm{CT} \rightarrow$ surg & $5 y, 39$ & $5 y, 47$ & $5 y, 30$ \\
\hline Das et al. ${ }^{48}$ & 50 & 2007 & $\mathrm{EBRT} / \mathrm{CT} \rightarrow$ surg & 48 & $3 y, 64$ & \\
\hline
\end{tabular}

Abbreviations: EBRT - external beam radiotherapy; CT - chemotherapy; IORT - intraoperative radiation; surg - surgery.

treated with the best supportive care. ${ }^{39,40}$ This is most probably the reason why the prognosis for patients with LRRC is on average worse in previously irradiated patients than in those without prior irradiation. Two Mayo Clinic studies demonstrated a better local control and survival when the palliative resection of LR was followed by IORT; however, in previously irradiated patients both outcome measures were lower than in patients not receiving prior EBRT: at 5-years, $34 \%$ vs $63 \%$ and $12 \%$ vs $20 \%$, respectively. ${ }^{30,41}$ In the randomized Stockholm trial comparing the preoperative irradiation to the surgical resection alone, $15 \%$ of irradiated patients suffered a local recurrence. They were treated with a variety of combinations of surgery, RT, and chemotherapy that resulted in a median survival of 11 months and no 5-yr survivors compared to 15 months in patients from surgery only group $(p=0.0002) .{ }^{42}$

Recent data suggest that limited doses of 30 Gy external beam Re-RT are likely to be safe, even when combined with concomitantly administered chemotherapy, if the small bowel can be excluded from the irradiation field, and an additional booster dose of up to $10 \mathrm{~Gy}$ can be used for limited volumes. ${ }^{43}$ Subsequent toxicity in re-irradiated patients is accaptable and resulted tumor shrinkage could be followed by surgical salvage and long-term survival in selected patients (Table 2). ${ }^{41,44-48}$ The irradiated volume usually encompasses recurrent tumor with a $2-4 \mathrm{~cm}$ margin. As the late intestinal toxicity strongly depends on the fractionation pattern used, hyperfractionation RT schedules with small fraction doses are preferred.

\section{Conclusions}

Despite the improved local control in rectal cancer achieved by preoperative chemoradiotherapy and TME surgery, a substantial proportion of patients will experience the local recurrence. A complete resection is crutial for achieving a long-term local control and survival. The addition of local high-dose radiation delivered in the form of IOERT or IO-HDR brachytherapy appears to have the potential to improve the treatment outcome after the extended surgery. However, in patients with gross residual disease after the surgical procedure, the local tumour control is inadequate despite aggressive treatment combinations. For a more accurate administration of higher radiation doses, advanced EBRT techniques such as 3D-conformal RT, intensity modulated radiotherapy (IMRT) and proton beam therapy are to be employed, whereas for the precise localisation of the disease, the integration of different imaging modalities is essential. To a further increase response rate, the evaluation of new radiation sensitizing drugs or biologic modifiers during EBRT is warranted. Because of the high probability of distant metastases, chemo- 
therapy should be an essential component of these aggressive treatment approaches. As LR is more common in patients with locally advanced tumours, who have already received 5-FU-based chemotherapy in the context of the primary treatment, a systemic therapy employing more effective novel agents is indicated.

\section{Acknowledgement}

The article resumes the lecture given by the author during the second edition of the international course "Oncology for surgeons" in Iasi, Romania on April 14-18, 2009.

\section{References}

1. Enker WE, Thaler HT, Cranor ML, Polyak T. Total mesorectal excision in the operative treatment of carcinoma of the rectum. J Am Coll Surg 1995; 181: 335-46.

2. Heald RJ, Moran BJ, Ryall RD, Sexton R, MacFarlane JK. Rectal cancer: the Basingstoke experience of total mesorectal excision, 1978-1997. Arch Surg 1998; 133: 894-9.

3. Kapiteijn E, Marijnen CA, Nagtegaal ID, Putter H, Steup WH, Wiggers T, et al. Preoperative radiotherapy combined with total mesorectal excision for resectable rectal cancer. N Engl J Med 2001; 345: 638-46.

4. Sauer R, Fietkau R, Wittekind C, Rodel C, Martus $\mathrm{P}$, Hohenberger $\mathrm{W}$, et al. Adjuvant vs neoadjuvant radiochemotherapy for locally advanced rectal cancer: the Germain trial CAO/ARO/AIO-94. Colorectal Dis 2003; 5: 406-15.

5. Frykholm GJ, Pahlman L, Glimelius B. Treatment of local recurrences of rectal carcinoma. Radiother Oncol 1995; 34: 185-94.

6. Gunderson LL, Sosin H. Area of failure found at reoperation following 'curative surgery' for adenocarcinoma of the rectum. Cancer 1974; 34: 1278-92.

7. Wanebo HJ, Koness J, Vezeridis MP, Cohen SI, Wrobleski DE. Pelvic resection of recurrent rectal cancer. Ann Surg 1994; 220: 586-97.
8. Oblak I, Strojan P, Zakotnik B, Budihna M, Smid L. Hemoglobin as a factor influencing the outcome in inoperable oropharyngeal carcinoma treated by concomitant radiochemotherapy. Neoplasma 2003; 50: $452-8$.

9. Velenik V, Oblak I, Kodre V. Managing anemia with epoetin alfa in patients with rectal cancer. Radiol Oncol 2005; 39: 133-40.

10. Tepper JE, O'Connell M, Niedzwiecki D, Hollis DR, Benson AB 3rd, Cummings B, et al. Adjuvant therapy in rectal cancer: analysis of stage, sex, and local control-Final report of intergroup 0114. J Clin Oncol 2002; 20: 1744-50.

11. Paty PB, Enker WE, Cohen AM, Lauwers GY. Treatment of rectal cancer by low anterior resection with coloanal anastomosis. Ann Surg 1994; 219: 365-73.

12. Phillips RKS, Hittinger R, Blesovsky L, Fry JS, Fielding LP. Local recurrence following 'curative' surgery for large bowel cancer: II. The rectum and rectosigmoid. Br J Surg 1984; 71: 17-20.

13. Adam IJ, Mohamdee MO, Martin IG, Scott N, Finan PJ, Johnston D, et al. Role of circumferential margin involvement in the local recurrence of rectal cancer. Lancet 1994; 344: 707-11.

14. Davies M, Harries D, Hirst G, Beynon R, Morgan $\mathrm{AR}$, Carr ND, et al. Local recurrence after abdomino-perineal resection. Colorectal Dis 2009; 11: 3943.

15. Sagar PM, Pemberton JH. Surgical menagement of locally recurrent rectal cancer. Br J Surg 1996; 83: 293-304.

16. Porter GA, Soskolne CL, Yakimets WW, Newman SC. Surgeon-related factors and outcome in rectal cancer. Ann Surg 1998; 227: 157-67.

17. Chong PS, Finlay IG. Surgical options in the management of advanced and recurrent colorectal cancer. Surg Oncol 2007; 16: 25-31.

18. Caricato M, Borzomati D, Ausania F, Valeri S, Rosignoli A, Coppola R. Prognostic factors after surgery for locally recurrent rectal cancer: an overview. Eur J Surg Oncol 2006; 32: 126-32.

19. Suzuki K, Dozois RR, Devine RM, Nelson H, Weaver AL, Gunderson LL, et al. Curative reoperations for locally recurrent rectal cancer. Dis Colon Rectum 1996; 39: 730-6.

20. Wanebo HJ, Gaker DL, Whitehill R, Morgan RF, Constable WC. Pelvic recurrence of rectal cancer: options for curative resection. Ann Surg 1987; 205: 482-95. 
21. Garcia-Aguilar J, Cromwell JW, Marra C, Lee $\mathrm{SH}$, Madoff RD, Rothenberger DA. Treatment of locally recurrent rectal cancer. Dis Colon Rectum 2001; 44: 1743-8.

22. Law W, Chu K. Resection of local recurrence of rectal cancer: results. World J Surg 2000; 24: 486-90.

23. Hahnloser D, Nelson H, Gunderson LL, Hassan I, Haddock MG, O'Connell MJ, et al. Curative potential of multimodality therapy for locally recurrent rectal cancer. Ann Surg 2003; 237: 502-8.

24. Suzuki K, Gunderson LL, Devine RM, Weaver AL, Dozois RR, Ilstrup DM, et al. Intraoperative irradiation after palliative surgery for locally recurrent rectal cancer. Cancer 1995; 75: 939-52.

25. Moriya Y. Treatment strategy for locally recurrent rectal cancer. Jpn J Clin Oncol 2006; 36: 127-31.

26. Camilleri-Brennan J, Steele R. The impact of recurrent rectal cancer on quality of life. Eur J Surg Oncol 2001; 27: 349-53.

27. Velenik V, Oblak I, Anderluh F. Quality of life in patients after combined modality treatment of rectal cancer: Report of a prospective phase II study. Radiol Oncol 2008; 42: 207-14.

28. Miller A, Cantor S, Peoples G, Pearlstone D, Skibber J. Quality of life and cost effectiveness analysis of therapy for locally recurrent rectal cancer. Dis Colon Rectum 2000; 43: 1695-703.

29. Wong CS, Cummings BJ, Brierley JD, Catton CN, McLean M, Catton P, et al. Treatment of locally recurrent rectal carcinoma-results and prognostic factors. Int J Radiat Oncol Bio Phys 1998; 40: 427-35.

30. Schild SE, Martenson J, Gunderson L, Dozois RR. Long-term survival and patterns of failure after postoperative radiation therapy for subtotally resected rectal adenocarcinoma. Int J Radiat Oncol Biol Phys 1989; 16: 459-63.

31. Gunderson LL, Nelson H, Martenson JA, Cha S, Haddock M, Devine R, et al. Intraoperative electron and external beam irradiation with or without 5-fluorouracil and maximum surgical resection for previously unirradiated, locally recurrent colorectal cancer. Dis Colon Rectum 1996; 39: 1379-95.

32. Lowy AM, Rich TA, Skibber JM, Dubrow RA, Curley SA. Preoperative infusional chemoradiation, selective intraoperative radiation, and resection for locally advanced pelvic recurrence of colorectal adenocarcinoma. Ann Surg 1996; 223: 177-85.
33. Farouk R, Nelson H, Gunderson LL. Aggressive multimodality treatment for locally advanced irresectable rectal cancer. Br J Surg 1997; 84: 741-9.

34. Wiig JN, Tveit KM, Poulsen JP, Olsen DR, Giercksky KE. Preoperative irradiation and surgery for recurrent rectal cancer. Will intraoperative radiotherapy (IORT) be of additional benefit? A prospective study. Radiother Oncol 2002; 62: 207-13.

35. Mannaerts GH, Rutten HJ, Martijn H, Hanssens $\mathrm{PE}$, Wiggers T. Comparison of intraoperative radiation therapy-containing multimodality treatment with historical treatment modalities for locally recurrent rectal cancer. Dis Colon Rectum 2001; 44: 1749-58.

36. Rades D, Kuhn H, Schultze J, Homann N, Brandenburg B, Schulte R, et al. Prognostic factors affecting locally recurrent rectal cancer and clinical significance of hemoglobin. Int J Radiat Oncol Biol Phys 2008; 70: 1087-93.

37. Syk E, Torkzad MR, Blomqvist L, Nilsson PJ, Glimelius B. Local recurrence in rectal cancer: anatomic localisaton and effect on radiation target. Int J Radiat Oncol Biol Phys 2008; 72: 658-64.

38. Yu TK, Bhosale PR, Crane C, Iyer RB, Skibber JM, Rodriguez-Bigas MA. Patterns of locoregional recurrence after surgery and radiotherapy or chemoradiation for rectal cancer. Int J Radiat Oncol Biol Phys 2008; 71: 1175-80.

39. Avradopoulos KA, Vezeridis MP, Wanebo HJ. Pelvic exenteration for recurrent rectal cancer. Adv Surg 1996; 29: 215-33.

40. Frykholm GJ, Pahlman L, Glimelius B. Treatment of local recurrences of rectal carcinoma. Radiother Oncol 1995; 34: 185-94.

41. Haddock MG, Gunderson LL, Nelson H, Cha SS, Devine RM, Dozois RR, et al. Intraoperative irradiation for locally recurrent colorectal cancer in previously irradiated patients. Int J Radiat Oncol Biol Phys 2001; 49: 1267-74.

42. Rutten HJ, Mannaerts GH, Martijn H, Wiggers T. Intraoperative radiotherapy for locally recurrent rectal cancer in The Netherlands. Eur J Surg Oncol 2000; 26(Suppl A): S16-20.

43. Glimelius B. Recurrent rectal cancer. The pre-irradiated primary tumour: can more radiotherapy be given? Colorectal Dis 2003; 5: 501-3.

44. Alektiar KM, Zelefsky MJ, Paty PB, Guillem J, Saltz LB, Cohen AM, et al. High-dose-rate intraoperative brachytherapy for recurrent colorectal cancer. Int $J$ Radiat Oncol Biol Phys 2000; 48: 219-26. 
45. Lindel K, Willett CG, Shellito PC, Ott MJ, Clark J, Grossbard $\mathrm{M}$, et al. Intraoperative radiation therapy for locally advanced recurrent rectal or rectosigmoid cancer. Radiother Oncol 2001; 58: 83-7.

46. Mohiuddin M, Marks G, Marks J. Long-term results of reirradiation for patients with recurrent rectal carcinoma. Cancer 2002; 95: 1144-50.

47. Valentini V, Morganti AG, De Franco A, Coco C, Ratto C, Battista Doglietto G, et al. Chemoradiation with or without intraoperative radiation therapy in patients with locally recurrent rectal carcinoma: Prognostic factors and long term outcome. Cancer 1999; 86: 2612-24.

48. Das P, Delclos ME, SkibberJM, Rodriguez-Bigas MA, Feig BW, Eng C, et al. Hyperfractionated accelerated radiotherapy for rectal cancer in patients with prior pelvic irradiation. [Abstract]. Int J Radiat Oncol Biol Phys 2007; 69(Suppl 1): S277 